\title{
Cadmium Removal by the Hydroponic Culture of Giant Reed (Arundo donax) and Its Concentration in the Plant
}

\author{
Masaki SAGEHASHI*, Chang LIU**, Takao FUJII***, Hirotaka FUJITA***, \\ Yuji SAKAI****, Hong-Ying HU*****, Akiyoshi SAKODA*** \\ *Center of Education for Leaders in Environmental Sectors, Tokyo University of \\ Agriculture and Technology, Tokyo 184-8588, Japan \\ **(Former Affiliation) Institute of Industrial Science, The University of Tokyo, Tokyo, \\ 153-8505, Japan \\ ***Institute of Industrial Science, The University of Tokyo, Tokyo 153-8505, Japan \\ ****Department of Environmental and Energy Chemistry, Kogakuin University, Tokyo \\ 192-0015, Japan \\ *****Environmental Simulation and Pollution Control State Key Joint Laboratory, School of \\ Environment, Tsinghua University, Beijing 100084,PR China
}

\begin{abstract}
Giant reed has high biomass productivity, and is a promising plant to be used for a constructed wetland system in which energy/material production and water purification are achieved simultaneously (multi-functional wetland). In this study, the cadmium removal by hydroponically cultured giant reed was observed, and its concentration in the plant body was measured to clarify the applicability of the wetland for cadmium treatment. The results suggested that the hydroponic culture of giant reed has high potential for cadmium removal. In addition, the inhibitory effect of cadmium on phosphorus removal, that is also important for water purification, was not observed under a concentration lower than $1 \mathrm{mg}-\mathrm{Cd} / \mathrm{L}$ for 7 days. After about 2 months of hydroponic culture the absorbed cadmium was highly concentrated in the rhizome. Furthermore, the positive correlation between glutathione (GSH) in the rhizome and cadmium removal rate was observed, indicating that the production of GSH was controlled by the cadmium assimilated in the giant reed.
\end{abstract}

Keywords: cadmium, giant reed, water purification

\section{INTRODUCTION}

Giant reed (Arundo donax), a perennial gramineous plant, has high biomass productivity (Papazoglou, 2007), and is a promising plant to be used in constructed wetlands for energy/material production and water purification. It can be called as the "multi-functional wetland". In the multi-functional wetland, the phosphorus recovery is important because of its exhaustibility and impact on algal growth, as well as the organic carbon production. Thus, carbon and phosphorus cycles system using giant reed are being proposed in this study. To realize this, studies on the phosphorus dynamics (Sagehashi et al., 2009), antialgal allelochemicals from giant reed (Hong et al., 2010), and cadmium removal by the charcoal prepared from giant reed (Sagehashi et al., 2010) had been performed.

On the other hand, it is widely known that various harmful heavy metals are removed with macrophytes (Ait Ali et al., 2004, Ghosh and Singh, 2005) as well as nutrients. This function is also important for the water purification by constructed wetlands. And to utilize this function sufficiently in the multi-functional wetland, understanding the characteristics of not only heavy metal removal but also its concentration in plant body

Address correspondence to Masaki Sagehashi, Center of Education for Leaders in Environmental Sectors, Tokyo University of Agriculture and Technology, Email: sagemasa@cc.tuat.ac.jp

Received: June 7, 2010, Accepted: September 22, 2010. 
is necessary for the adequate utilization of the produced biomass.

Naturally, various toxic heavy metals pollute the water environment. In this study, we especially focused on cadmium removal from the surface water by constructed wetland, because of its toxicity (e.g., Shimoi et al., 2007), and widespread existence in the environment (Das et al., 1997). Until today, some researches have been reporting on the tolerance of giant reed for cadmium (Papazoglou et al., 2005, 2007; Papazoglou 2007). However, to our knowledge, the information of the dynamics of cadmium in giant reed cultivated wetland is not enough to design the multi-functional wetland. The purposes of this study are thus to clarify the dynamics of cadmium removal by giant reed, and investigate its concentration in plant body.

The dynamics of cadmium in soil zone is, however, complicated. Firstly, the adsorption of cadmium on soil surface is expected and under reducing condition, very insoluble cadmium sulfide is formed. To highlight the removal of soluble cadmium compounds in plant, the hydroponic culture like that of Ait Ali et al. (2004) was employed in this study.

On the other hand, it is known that phytochelatins (PCs) can chelate cadmium, and is synthesized from glutathione (GSH). Inouhe et al. (1994) reported that the cadmium binding complex containing PCs has an important role for the cadmium-tolerance of seedlings of some gramineous plants, i.e., maize, oat, barley, and rice. Thus, the dynamics of cadmium in giant reed culture seems to affect the GSH production. Therefore, the production property of GSH in giant reed was also measured in this study.

\section{MATERIALS AND METHODS \\ Giant Reed}

Fertilized giant reed grown at a managed area in the Kanto Plain, Japan, was used for experiments. The plant body including rhizomes was plowed up, and transferred to the Institute of Industrial Science, the University of Tokyo. Prior to laboratory experiments, the giant reed was cultured in the outdoor flowerbed.

\section{Hydroponic Culture}

A circulating hydroponic culture system shown in Fig. 1 was employed in this study. These apparatuses were installed in an experimental room in which the temperature was kept at about $25^{\circ} \mathrm{C}$. The composition of the culture broth shown in Table 1 was basically the same as that in the previous study (Sagehashi et al., 2009). The volume of the total culture broth was set as $2 \mathrm{~L}$ and was circulated by a liquid pump. To avoid the direct effects on the removal of cadmium and phosphorus by parts other than the rhizome, the water level of the cultivation pot was kept lower than the top of the rhizome by an overflow port. The light source was a fluorescent lamp for cultivating plants, and the light / dark cycle was set as 14 hours / 10 hours in a day. Sampling was performed once a day by an automatic sampler.

Experimental conditions are shown in Table 2. To clarify the effect of cadmium on phosphorus removal, 5 runs (Run 1 to 5) were performed using giant reed. An 




Fig. 1 - Hydroponic culture apparatus

Table 1 - Components of culture broth

\begin{tabular}{cc}
\hline Component & Concentration [mg/L] \\
\hline$\left(\mathrm{NH}_{4}\right)_{2} \mathrm{SO}_{4}$ & 10 \\
\hline $\mathrm{Na}_{2} \mathrm{HPO}_{4} \cdot 12 \mathrm{H}_{2} \mathrm{O}$ & 20 \\
\hline $\mathrm{KCl}$ & 10 \\
\hline $\mathrm{CaCl}_{2}$ & 2 \\
\hline $\mathrm{MgCl}_{2} \cdot 6 \mathrm{H}_{2} \mathrm{O}$ & 2 \\
\hline $\mathrm{FeCl}_{3}$ & 3 \\
\hline $\mathrm{MnCl}_{2} \cdot 4 \mathrm{H}_{2} \mathrm{O}$ & 0.1 \\
\hline
\end{tabular}

Table 2 - Experimental conditions

\begin{tabular}{ccc}
\hline Run \# & $\begin{array}{c}\text { Initial cadmium conc. in culture } \\
\text { medium [mg-Cd/L] }\end{array}$ & $\begin{array}{c}\text { Initial phosphorus conc. in } \\
\text { culture medium }\end{array}$ \\
\hline \hline 1 & 1.0 & 2.0 \\
2 & 1.0 & 1.8 \\
3 & 1.0 & 1.4 \\
4 & 0.0 & 1.7 \\
5 & 0.0 & 1.7 \\
\hline 6 & $(\mathrm{a})$ & 2.0 \\
\hline 7 & 2.0 & 2.0 \\
8 & 0.0 & 2.0 \\
\hline & (a) At the start of the experiment, the initial concentration of cadmium was \\
& set to 1.0 mg/L and after 55 days, the cadmium concentration was increased
\end{tabular}

experiment to clarify the concentration of cadmium in the body of giant reed was also performed using the same experimental apparatus (Run 6). In Run 6, the rhizome was firstly immersed in the culture broth of $1 \mathrm{mg}-\mathrm{Cd} / \mathrm{L}$. After 55 days, the cadmium concentration was increased to $5 \mathrm{mg}-\mathrm{Cd} / \mathrm{L}$ by extra addition and cultivated for 14 days. Meanwhile, the dynamics of GSH in giant reed as a result of contact with cadmium was also measured using the same apparatus (Runs 7 and 8). Giant reeds of about $1 \mathrm{~m}$ in height were used in all experiments except for Run 6. In Run 6, a small rhizome without stalk and leaf was used to clarify the cadmium assimilation in plant body within the active growth stage. 


\section{Analyses}

The concentrations of water with dissolved cadmium and phosphorus were determined using a spectrophotometer (pHotoFlex, WTW, Germany). The concentration of GSH was measured by colorimetric method using a measurement kit (BIOXYTECH GSH-420, OXIS Health Product, Porland). For the measurement of cadmium content in giant reed, its leaf, stalk, and rhizome were firstly immersed in Tris- $\mathrm{HCl}$ buffer at $0^{\circ} \mathrm{C}$ for extraction. Then, extracts were treated with $\mathrm{HCl}$, and the concentration of cadmium was measured by the method mentioned previously.

\section{RESULTS AND DISCUSSION}

\section{Removal of cadmium and phosphorus}

Time courses of cadmium concentrations in culture broth in Run 1 to 3 are shown in Fig. 2. More than $60 \%$ of cadmium was removed within 7 days in every run. Assuming the zero-order kinetics, the average cadmium removal rates within the 7 days calculated from the linear approximations of the plots in Fig. 2 were estimated as 0.12 to 0.15 $\mathrm{mg}-\mathrm{Cd} / \mathrm{day} /$ plant. Ait Ali et al. (2004) reported the cadmium accumulation rate by common reed (Phragmites australis) as $14.7 \mu \mathrm{g} /$ day/g-DW under $2 \mathrm{mg}-\mathrm{Cd} / \mathrm{L}$. Considering the plant weight, it can be regarded as about $0.03 \mathrm{mg}-\mathrm{Cd} / \mathrm{day} / \mathrm{plant}$. With regards to the discrepancy in size (The height of the common reed used in Ait Ali et al. (2004) was $30 \mathrm{~cm}$, while giant reed used in this study was about $1 \mathrm{~m}$.), the removal rate observed in this study was not much different to the accumulation rate of common reed reported by Ait Ali et al. (2004). There is a possibility of the immobilization of dissolved cadmium by microorganisms in the culture, and more detailed analysis about cadmium balance is required for accurate estimation of the assimilation rate by the giant reed. However, the overall tendency was clarified in this study. Meanwhile, the decreasing rate of the cadmium concentration was higher in early period. This is another aspect which is presented in the succeeding discussion with the dynamics of GSH.

The time courses of phosphorus concentrations in Run 1 to 5 are shown in Fig. 3. These phosphorus removal rates were also calculated from the linear approximation with the assumption of zero-order kinetics. As a result, the rates were estimated as 0.05 to 0.16 $\mathrm{mg}-\mathrm{P} /$ day/plant with cadmium addition, and 0.09 to $0.14 \mathrm{mg}-\mathrm{P} / \mathrm{day} / \mathrm{plant}$ without cadmium addition. This result indicated that the addition of cadmium $(1 \mathrm{mg}-\mathrm{Cd} / \mathrm{L}) \mathrm{had}$ no effect on the phosphorus removal within 7 days in hydroponic culture. Meanwhile,

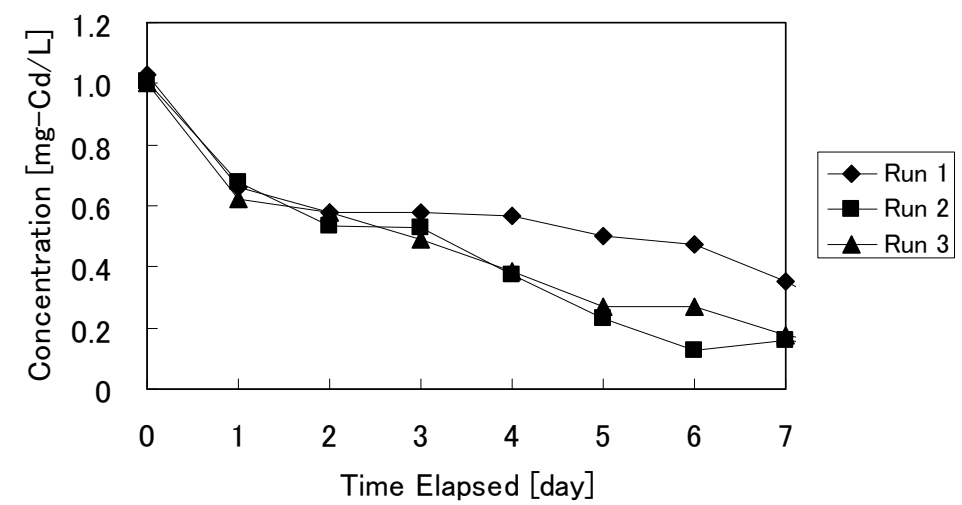

Fig. 2 - Time course of cadmium concentration in the culture broth (Runs 1 to 3) 
the rapid decrease in the concentration at the early stage like in the case of cadmium was not observed. Furthermore, the particular effect of the cadmium addition on the appearance of the plant body was not observed during 7 days in runs 1 to 5 .

\section{Assimilation of cadmium in giant reed}

Fig. 4 shows the cadmium concentration in giant reed as a result of Run 6, indicating that the cadmium was highly concentrated in the rhizome. The transportation index, $T_{i}$, indicates the ability of the plant to translocate the metal species from roots to leaves and can be calculated by the following equation (Ghosh and Singh, 2005).

$$
T_{i}=\frac{\text { Cadmium in leaves }(\mathrm{mg} / \mathrm{kg})}{\text { Cadmium in roots }(\mathrm{mg} / \mathrm{kg})} \times 100
$$

In this study, $T_{i}$ is estimated as about 2 from the result shown in Fig. 4. Ghosh and Singh (2005) reported $T_{i}=54.3$ for Phragmytes karka under $10 \mathrm{mg}-\mathrm{Cd} / \mathrm{kg}$-soil condition for a 90-day experiment. The simple comparison is difficult because of the difference in experimental condition and the experimental period. However, this result suggests that the translocation of cadmium in giant reed under hydroponic culture is not so active.

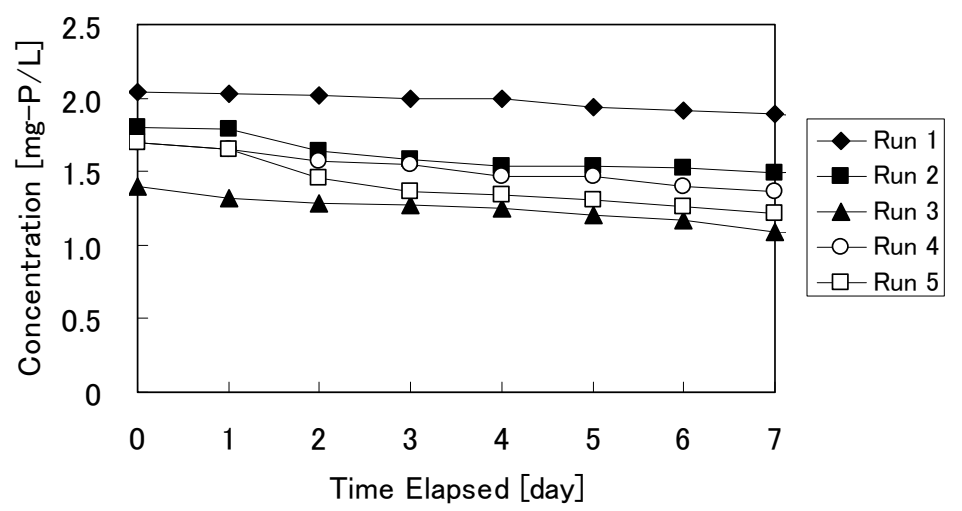

Fig. 3 - Time course of phosphorus concentration in the culture broth (Runs 1 to 5)

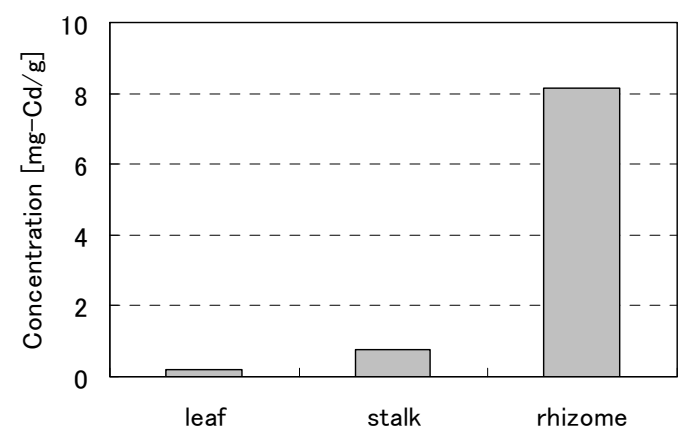

Fig. 4 - Concentration of cadmium in giant reed (Run 6) 


\section{Effect of glutathione on cadmium uptake}

The variation of GSH in giant reed was compared in cases where cadmium was added (Run 7) and not added (Run 8). The results as well as the change in cadmium concentration in culture medium are shown in Fig.5. The large decrease was observed between 0 and 1 day and the temporal increase of GSH in Run 7 was clarified. When the decrease of the cadmium concentration was large, the GSH concentration was high. After day 1, the concentration of cadmium seemed to increase. However, it was considered that it was within the range of experimental error. This result indicated that the GSH and subsequently produced phytochelatins affect the neutralization of toxic effects of cadmium that accumulated in the giant reed, which is similar to those of other gramineous plants (Inouhe et al., 1994).

\section{CONCLUSIONS}

The giant reed has high potential for cadmium removal in hydroponic culture. In this study, the removal rate was estimated as 0.12 to $0.15 \mathrm{mg}-\mathrm{Cd} /$ day/plant after contact with cadmium solution of $1 \mathrm{mg}-\mathrm{Cd} / \mathrm{L}$ for 7 days. The effect of cadmium on phosphorus removal was not observed in this condition. It was also elucidated that cadmium was highly concentrated in the rhizome. Furthermore, the production of GSH in the rhizome seems to be affected by the assimilated cadmium.

\section{ACKNOWLEDGEMENT}

This work was partly supported by Japan Science and Technology Agency (JST) National Natural Science Foundation of China (NSFC) Joint Program (Strategic International Cooperative Program).

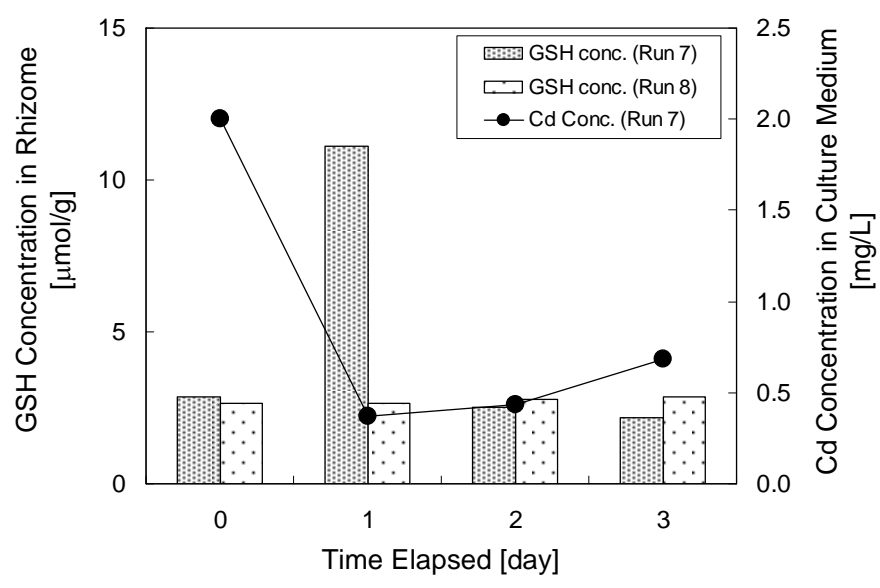

Fig. 5 - Changes in GSH concentration in the rhizome of giant reed and its phosphorus uptake (Runs 7 and 8) 


\section{REFERENCES}

Ait Ali N., Bernal M. P. and Ater M. (2004). Tolerance and bioaccumulation of cadmium by Phyragmites australis grown in the presence of elevated concentrations of cadmium, copper, and zinc, Aquat. Bot., 80, 163-176.

Das P., Samantaray S. and Rout G. R. (1997). Studies on cadmium toxicity in plants: A review, Environ. Pollut., 98(1), 29-36.

Ghosh M. and Singh S. P. (2005). A comparative study of cadmium phytoextraction by accumulator and weed species, Environ. Pollut., 133, 365-371.

Hong Y., Hu H. Y., Sakoda A. and Sagehashi M. (2010). Isolation and characterization of antialgal allelochemicals from Arundo donax L., Allelopathy J., 25(2), 357-368.

Inouhe M., Ninomiya S., Tohoyama H., Joho M. and Murayama T. (1994). Different characteristics of roots in the cadmium-tolerance and Cd-binding complex formation between mono- and dicotyledonous plants, J. Plant Res., 107, 201-207.

Papazoglou E. G. (2007). Arundo donax L. stress tolerance under irrigation with heavy metal aqueous solutions, Desalination, 211(1-3), 304-313.

Papazoglou E. G., Karantounias G. A., Vemmos S. N. and Bouranis D. L. (2005). Photosynthesis and growth responses of giant reed (Arundo donax L.) to the heavy metals $\mathrm{Cd}$ and Ni, Environ. Int., 31, 243- 249.

Papazoglou E. G., Serelis K. G. and Bouranis D. L. (2007). Impact of high cadmium and nickel soil concentration on selected physiological parameters of Arundo donax L., Eur. J. Soil Biol., 43, 207-215.

Sagehashi M., Kawazoe A., Fujii T., Hu H. Y. and Sakoda A. (2009). Analysis of phosphorus behavior in the giant reed for phytoremediation and the biomass production system, J. of Water and Environ. Technol., 7(2), 143-154.

Sagehashi M., Fujii T., Hu H. Y. and Sakoda A. (2010). Removal of cadmium from aqueous solutions by charcoals prepared from giant reed (Arundo donax), J. of Water and Environ. Technol., 8(4), 305-312.

Shimoi G., Kameyama Y., Hashizume R. and Ito M. (2007). The effects of cadmium toxicity on maturation and fertilization process of mouse oocytes, J. Mamm. Ova Res., 24, 161-166. (in Japanese) 